\title{
Seasonal changes in Arctic sea-ice morphology
}

\author{
Donald K. Perovich, Jagqueline A. Righter-Menge, Walter B. Tugker, III \\ U.S. Army Cold Regions Research and Engineering Laboratory, 72 Lyme Road, Hanover, NH 03755-1290, U.S.A.
}

\begin{abstract}
The morphology of the Arctic sea-ice cover undergoes large changes over an annual cycle. These changes have a significant impact on the heat budget of the ice cover, primarily by affecting the distribution of the solar radiation absorbed in the ice-ocean system. In spring, the ice is snow-covered and ridges are the prominent features. The pack consists of large angular floes, with a small amount of open water contained primarily in linear leads. By the end of summer the ice cover has undergone a major transformation. The snow cover is gone, many of the ridges have been reduced to hummocks and the ice surface is mottled with melt ponds. One surface characteristic that changes little during the summer is the appearance of the bare ice, which remains white despite significant melting. The large floes have broken into a mosaic of smaller, rounded floes surrounded by a lace of open water. Interestingly, this break-up occurs during summer when the dynamic forcing and the internal ice stress are small. During the Surface Heat Budget of the Arctic Ocean (SHEBA) field experiment we had an opportunity to observe the break-up process both on a small scale from the ice surface, and on a larger scale via aerial photographs. Floe break-up resulted in large part from thermal deterioration of the ice. The large floes of spring are riddled with cracks and leads that formed and froze during fall, winter and spring. These features melt open during summer, weakening the ice so that modest dynamic forcing can break apart the large floes into many fragments. Associated with this break-up is an increase in the number of floes, a decrease in the size of floes, an increase in floe perimeter and an increase in the area of open water.
\end{abstract}

\section{INTRODUCTION}

Profound changes occur in the appearance and morphology of the Arctic sea-ice cover over an annual cycle. In spring the ice cover consists of large floes separated by narrow, long, linear leads. The ice is snow-covered, with a uniform, bright appearance and a high albedo. By the height of the melt season, conditions have changed dramatically. The ice cover becomes an ensemble of many smaller, individual floes surrounded by a lace of open water. The surface is a variegated mixture of bare ice, melt ponds and leads. These changes are illustrated in Figure 1 by photographs taken on 20 May 1998 and 7 August 1998. Attendant with these changes in ice morphology is a decrease in the albedo of the ice cover (Perovich and others, in press b).

While it is recognized that the ice-albedo feedback is important, there is considerable uncertainty in the appropriate way to treat it in large-scale sea-ice models and in general circulation models (Ingram and others, 1989; Rind and others, 1995). This uncertainty provided the motivation for SHEBA, a research program on the Surface Heat Budget of the Arctic Ocean (Moritz and others, 1993; Moritz and Perovich 1996). A key part of the SHEBA program was a year-long field experiment in the Arctic pack ice (Perovich and others, 1999b). During SHEBA we had an opportunity to observe the evolution in the morphology and appearance of the ice cover from winter to spring to summer to fall. Understanding these changes in the appearance and morphology of the ice cover is critical to understanding the ice-albedo feedback and the distribution of solar energy within the ice- ${ }^{-}$ocean system.
In this paper we will first discuss the changes in icecover morphology that occur in summer, and explore the processes responsible for these changes. This will be done both qualitatively and quantitatively, and on a small scale and a large scale. The increase in pond fraction and lead fraction during the summer is striking (Fig. 1). However, there are other features that are less obvious, though equally intriguing: the white ice and fragmented floes. How does the white ice stay white? How do the floes fragment, when the ice is in free drift? We shall explore these questions. Finally we will examine the impact of these changes on the distribution of solar energy within the ice cover.

\section{METHODS}

The SHEBA field experiment lasted from October 1997 through October 1998. During this time the SHEBA team made a comprehensive suite of measurements defining the state of the atmosphere, ice and ocean (Perovich and others, 1999b) at the SHEBA site as it drifted through the Beaufort and Chukchi Seas. The focus of our group was on the ice mass balance and optical properties (Perovich and others, 1999a). A key feature of the SHEBA field experiment was spending a year on the ice studying the same ice floes; observing ice growth and dynamic events during winter, and monitoring the changes in the ice cover during the summer melt season. Ice growth, ablation and changes in surface characteristics were measured throughout the experiment at more than 100 locations. During summer, mass-balance measurements were made every other day. The evolution of albedo and surface characteristics was 
a

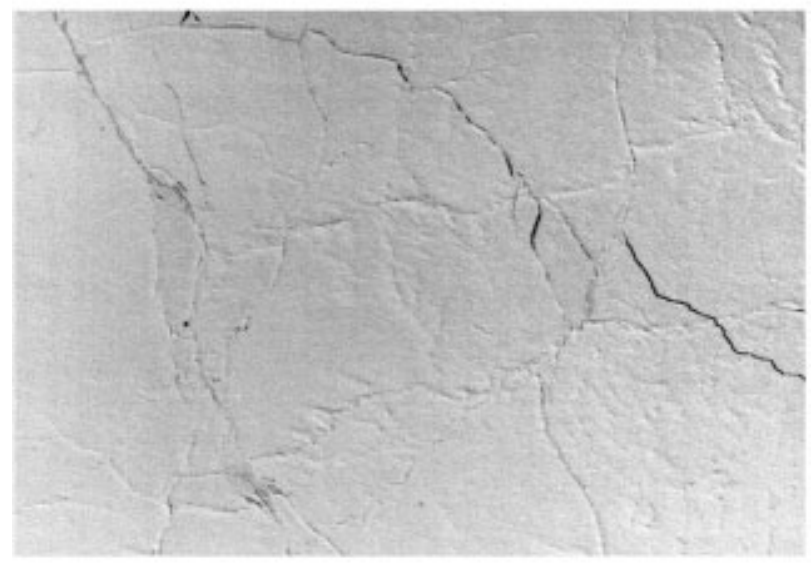

b

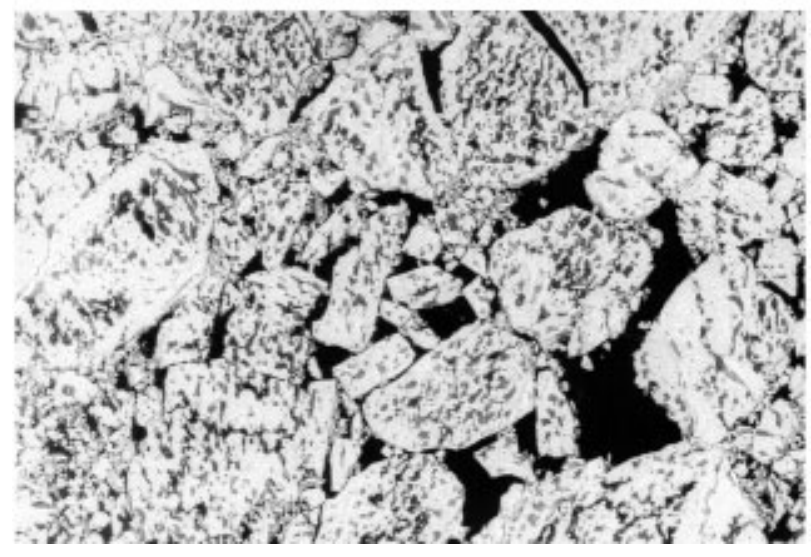

Fig. 1. Representative aerial photographs of the pack ice near SHEBA on (a) 20 May 1998 and (b) 7 August 1998. The photographs were taken at an altitude of $1800 \mathrm{~m}$ and the scale is $1260 \mathrm{~m}$ along the long edge of the photograph.

monitored from April through October along a $200 \mathrm{~m}$ long survey line (Perovich and others, in press b).

Complementing the surface-based observations were photography flights made using the ship's helicopter at approximately 1-2 week intervals from mid-May 1998 through the end of the experiment in October 1998. The flights were made at an altitude of $1800 \mathrm{~m}$ and surveyed a $50 \mathrm{~km} \times 50 \mathrm{~km}$ box centered on the ship (Perovich and others, in press a). Approximately 200 photographs, each covering an area of approximately $1.1 \mathrm{~km}^{2}$, were taken during each flight. These photographs were analyzed using image-processing software (Perovich and Tucker, 1997) to determine the relative portions of ice, melt ponds and open water in each image, as well as the floe perimeter.

\section{RESULTS}

The major impact that summer melt has on ice morphology is evident in Figure 1. Between 20 May and 7 August, the snow-covered ice is transformed into snow-free, bare ice, covered with significant portions of melt ponds. Surprisingly, even after 2 months of surface ablation, there still appears to be a substantial amount of white ice. In addition, the large plate-like floes separated by long, narrow leads changed into a complex mosaic replete with a multitude of individual floes interlaced with open water.

\section{a}

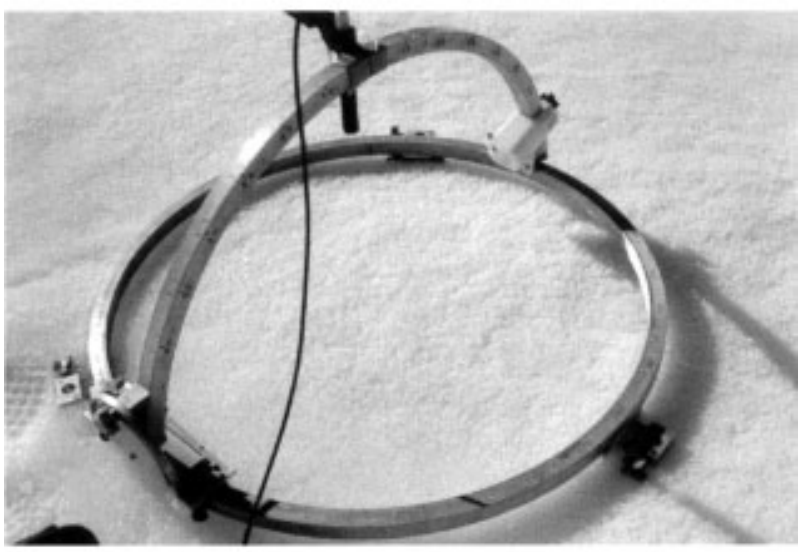

$\mathrm{b}$

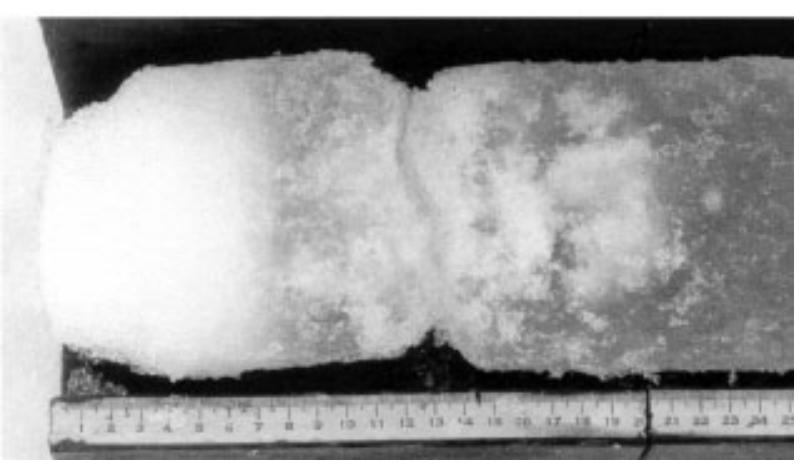

Fig. 2. (a) Close-up photograph of the surface scattering layer of white ice. The footprint on the lefthand side shows the depth of this layer. The ring in the photograph is used to measure bidirectnal reflectance. (b) Photograph of an ice core removed from multi-year ice. There is a $7 \mathrm{~cm}$ thick drained layer at the top of the ice core that evolves into the surface scattering layer.

\section{White ice: surface scattering layer}

Melt ponds are the most eye-catching feature of the summer ice surface, and their formation and evolution strongly impacts the ice-albedo feedback (Grenfell and Maykut, 1977; Ebert and others, 1995; Fetterer and Untersteiner, 1998; Perovich and others, in press b). A more subtle but equally important observation, which also impacts the ice-albedo feedback process, is that the ice stays white. During summer much of the ice surface is covered by a thin $(1-3 \mathrm{~cm})$ granular layer. Figure 2a shows a close-up photograph of this surface layer. The footprint on the lefthand side of the photograph shows that this surface layer is soft and is a few centimeters thick. At first glance this ubiquitous layer appears to be a thin layer of melting, well-metamorphosed rounded snow grains, each a few millimeters across. However, we know that this is not the case, as virtually all of the snow cover had melted by late June. Mass-balance measurements also showed that, on average, there was $50-100 \mathrm{~cm}$ of surface ablation at unponded sites during the summer. The surface granular layer is deteriorated ice. Our observations indicate that as surface ablation progresses, the ice fragments, developing a surface granular layer that continually renews itself during melt.

The deterioration of the surface layer is a direct result of the structural and optical properties of sea ice. Structurally, sea ice is a matrix of individual ice crystals containing an 
amalgam of ice platelets, brine pockets and air bubbles (Weeks and Ackley, 1982). Sea ice is also a translucent medium, where solar energy penetrates, resulting in internal melting preferentially along the grain boundaries. The surface layer of melting multi-year ice is porous and above freeboard, so meltwater can readily drain. A $10 \mathrm{~cm}$ diameter ice core taken from the top of the ice is displayed in Figure 2b. The top $7 \mathrm{~cm}$ of this core were drained and appeared white. All of the ice cores we examined had a drained surface layer ranging from 5 to $30 \mathrm{~cm}$ in thickness. Densities in this drained layer were $0.6-0.8 \mathrm{~g} \mathrm{~cm}^{-3}$, compared to values of about $0.9 \mathrm{~g} \mathrm{~cm}^{-3}$ in the underlying ice. This drained layer is the breeding ground for the surface granular layer. Once the meltwater drains, the surface layer becomes friable and is easily broken apart into small fragments. The process of drainage and fragmentation results in a surface granular layer that continually renews itself as surface melting progresses. The surface layer has a white appearance because of its low density and high air volume. These air-filled pores scatter the incoming light, creating the white appearance of the surface.

To confirm the hypothesis that the white ice was the result of a perpetually draining surface layer, we repeated an experiment performed by Untersteiner (1961). We scraped away the surface granular layer down to bare ice. Indeed, by the next day a surface granular layer had re-formed on this site. Such layers have been reported in the past (Untersteiner, 1961; Grenfell and Maykut, 1977; Zubov, 1979; Williams, 1994; Eicken and others, 1995; Tucker and others, 1999). At SHEBA we determined that these layers continually renewed themselves during the melt season.

While the layer of coarse, loose ice grains was ubiquitous and pervasive, it did vary in thickness. Observations made at mass-balance sites (Perovich and others, 1999a) showed that the layer typically was $1-3 \mathrm{~cm}$ thick. Qualitative observations indicated that this layer tended to become thicker on sunny days and thinner on cloudy days. This was a result of two factors: penetrating solar energy and surface ablation. Penetrating solar energy thickens the layer, and surface ablation thins the layer. Mass-balance studies (Perovich and others, in press a) indicated that there tended to be more surface ablation on cloudy days than sunny days, thinning the granular layer. In contrast, the incident, and penetrating, solar energy is greater on clear days, causing more internal melting and greater development of the granular layer.

Because of the self-renewing surface scattering layer the white-ice albedo typically remained in the $0.65-0.70$ range throughout the summer. Grenfell and Maykut (1977) reported an albedo of 0.5 for bare ice without a surface scattering layer. The effect of the surface scattering layer on areally averaged albedo is significant. For instance, if there were no surface scattering layer on 7 August the white-ice albedo would have been 0.5 instead of 0.67 , giving an areally averaged albedo of only 0.35 , half the 15 June value.

\section{Break-up}

During summer, lateral melting around the perimeters of ice floes results in an increase in the amount of open water. Increases in open water can also result from ice dynamics. At Ice Station SHEBA, there was a sharp increase in open water in early August due to ice dynamics; wind stresses on the ice cover caused divergence of the ice floes (RichterMenge and others, 2001). Because air temperatures are consistently near $0^{\circ} \mathrm{C}$ and the incoming solar radiation is at a a

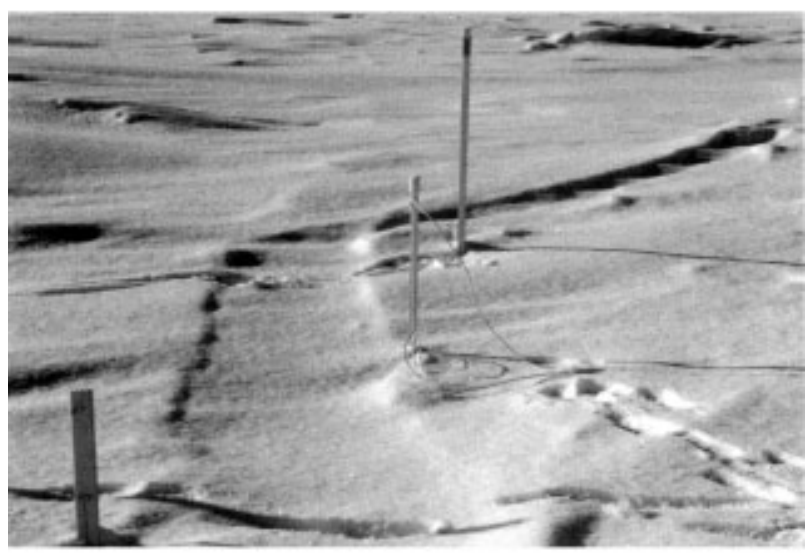

$\mathrm{b}$

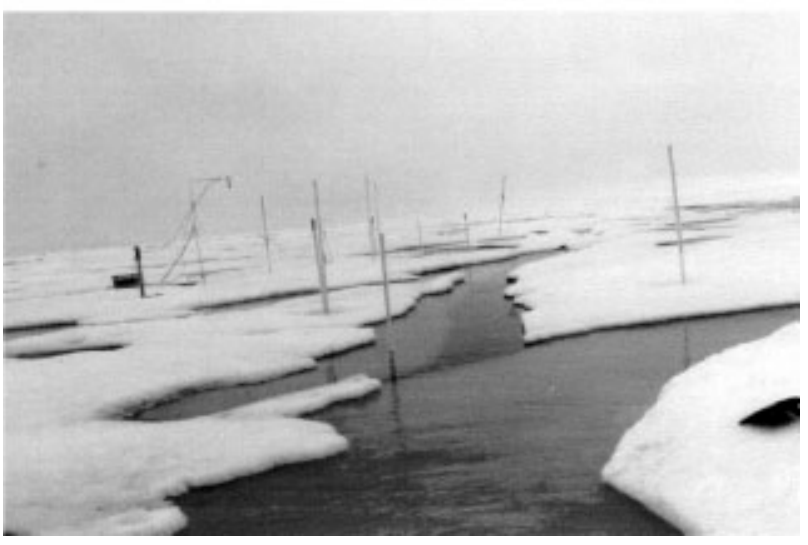

Fig. 3. Photographs of a crack in the ice that formed in fanuary 1998. The photographs were taken in (a) April 1998 and (b) July 1998. There was preferential melting in the crack as the melt season progressed.

maximum during the summer, any open water produced by either melting or dynamics will not freeze over. This explains why the amount of open water increases, but it does not account for the break-up of the ice floes. Observations and models have determined that in the central Arctic for most of the summer, internal ice stresses are near zero, and the movement of the ice cover becomes more strongly correlated with wind and ocean forcing (McPhee, 1980; Steele and others, 1997). This is consistent with measurements of the ice drift and internal ice stresses taken at SHEBA (Richter-Menge and others, 1998, 2001; Perovich and others, 1999a). Under these conditions, the ice is in a state of free drift, and forces that can break up the ice cover due to the dynamic interaction of ice floes are minimal. Hence, we believe that the summer floe break-up resulted from thermodynamic weakening of the ice.

There was dynamic activity in the ice pack throughout the winter. In the immediate vicinity of Ice Station SHEBA there were major stress-deformation events in the period January-March, resulting in the formation of cracks, leads and ridges (Richter-Menge and others, 1998). The cracks and leads rapidly froze and were covered by drifting snow, effectively disappearing. When the snow melted in early June, a winter's worth of cracks suddenly reappeared and acted as the starting-points for break-up. The photographs in Figure 3 demonstrate this. In January, multi-year ice 
a

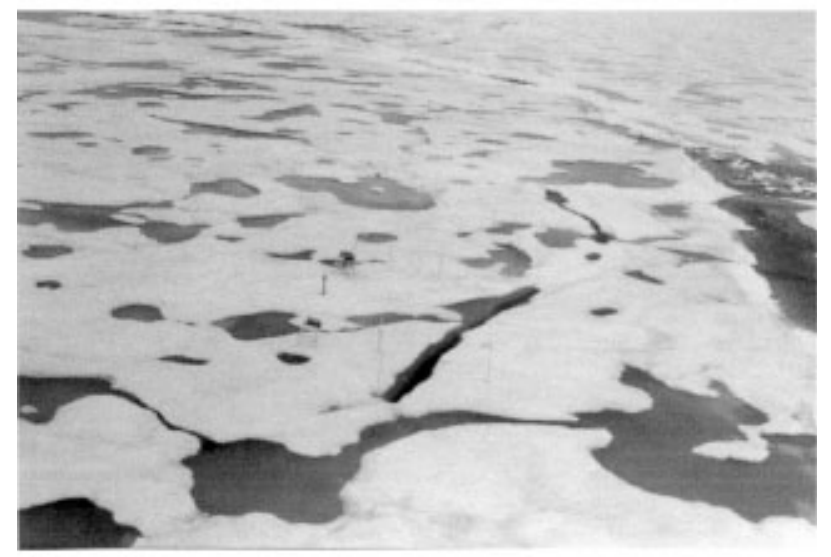

b

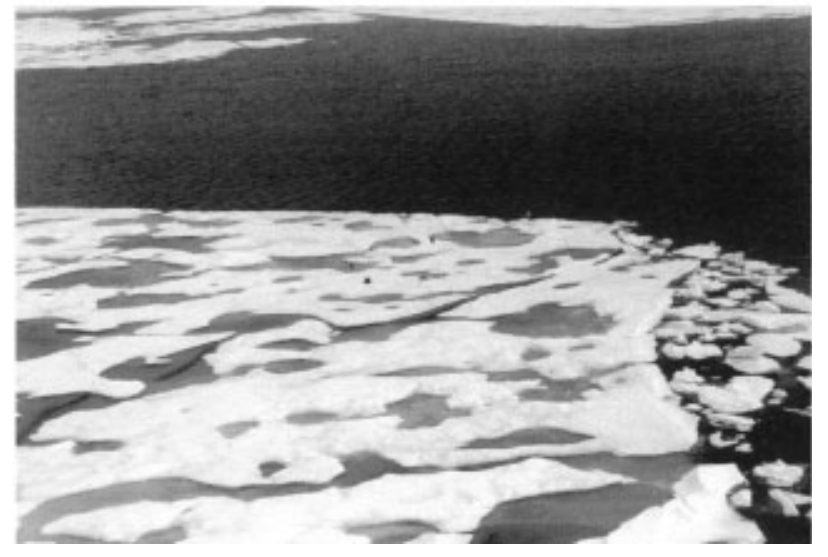

Fig. 4. Helicopter photographs taken of the site pictured in Figure $3(a)$ before and $(b)$ after the divergence event in early August.

adjacent to our "Quebec" site (Perovich and others, 1999a) broke apart forming a $0.5 \mathrm{~m}$ wide crack. By April this crack was solidly frozen and snow-covered (Fig. 3a). As the melt season, which began in late May, progressed, the crack preferentially melted and was the first place to melt through to the ocean (Fig. 3b). There are several reasons for the preferential melting of cracks. First, the ice in cracks is thinner than the adjacent multi-year ice. The cracks also melt faster because they are first-year ice and, once the snow has melted, have a lower albedo than the more highly scattering multi-year ice (Grenfell and Maykut, 1977). The thinner ice in the cracks also had a lower freeboard, so, unlike the multi-year ice with the self-renewing white surface layer, it could not develop much of a surface scattering layer due to drainage. Finally, being topographically lower, the cracks tended to collect meltwater, further reducing their albedo.

By the end of July, thermal deterioration of the cracks was well advanced and the floes were primed to fall apart. Walking surveys on the ice showed that ice in the cracks had almost completely melted and in many places the floes were barely held together. In addition, some melt ponds had melted through to the ocean, further weakening the ice. Winds were light during most of July and there was only modest ice drift. The wind increased at the end of July and the ice drift increased as the pack moved in concert. At the beginning of August the wind decreased, and the floes

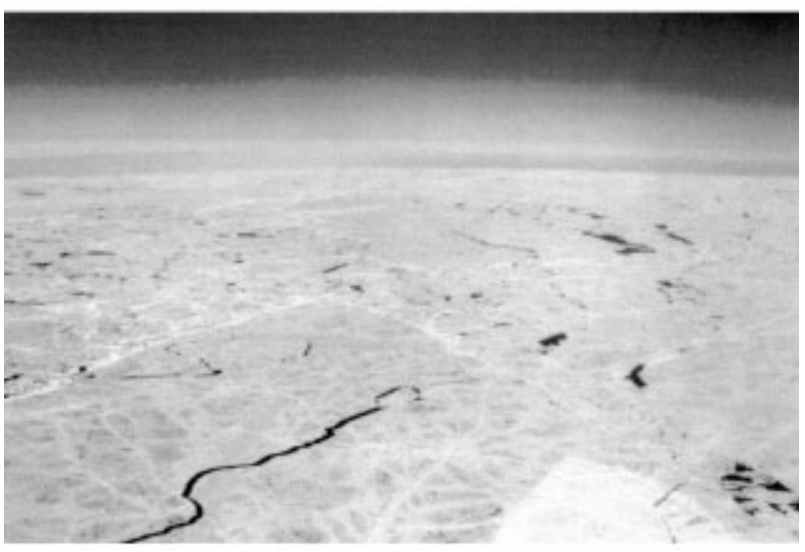

$\mathrm{b}$

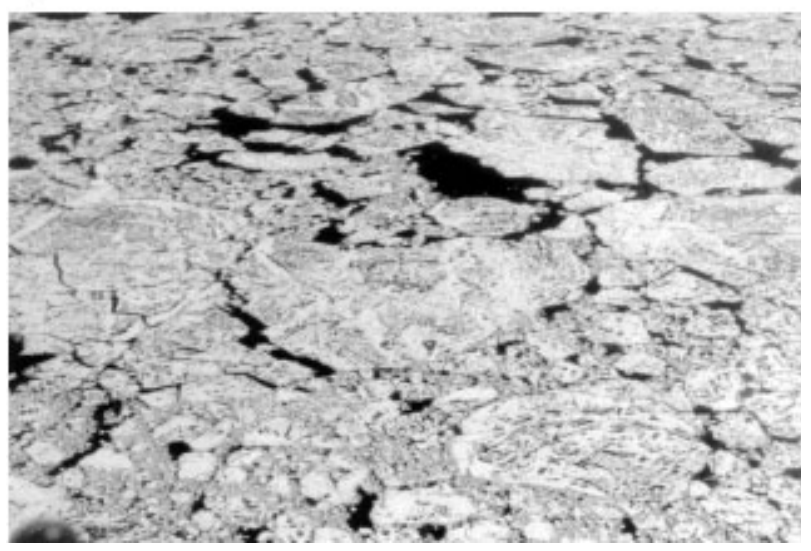

Fig. 5. Aerial photographs taken at an altitude of $1800 \mathrm{~m}$ on (a) 15 June 1998 and (b) 7 August 1998.

began to slow down, diverge and break apart (RichterMenge and others, 2001). This was the major divergence event of the summer, resulting in an increase in the amount of open water from $5 \%$ to $20 \%$ in the area around Ice Station SHEBA (Perovich and others, in press a). Figure 4 shows before and after photos illustrating the impact of this divergence event at the Quebec site. The area around Quebec fragmented into several pieces along the flaw lines of the melting cracks. We observed similar behavior at the other mass-balance sites. Three of our sites (Quebec, Seattle and the Mainline) were located within a few hundred meters of each other. After the divergence event these sites were on individual floes and were separated by as much as a few kilometers. The aerial photographs in Figure 5 show this break-up on a larger scale. The photographs were taken on 15 June and 7 August 1998 from an altitude of approximately $1800 \mathrm{~m}$. The differences are obvious: on 7 August there is much more open water and the large plates of ice from 15 June have fragmented into many more smaller floes.

To quantify these changes in the characteristics of the ice cover between 15 June and 7 August, we analyzed aerial photographs from these days taken along a $50 \mathrm{~km} \times 50 \mathrm{~km}$ box surrounding the ice station (Perovich and others, in press a). Photographs covering a total area of $180 \mathrm{~km}^{2}$ on 15 June (164 photographs) and $153 \mathrm{~km}^{2}$ on 7 August (139 photographs) were processed to determine the area fractions of ice, ponds and leads (Fig. 6). For each day we selected a subset of images and determined the total floe perimeter in those images. Since each photograph was only $1.1 \mathrm{~km}^{2}$, and 


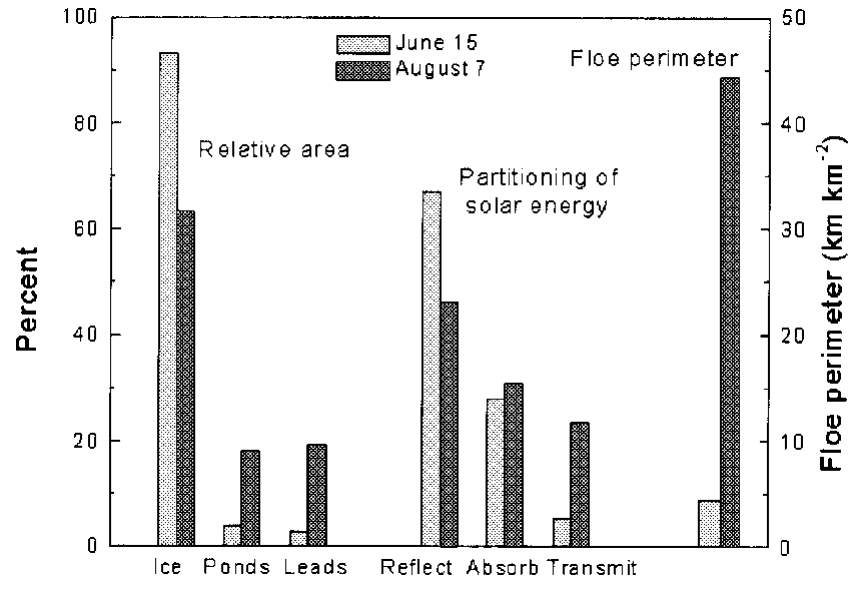

Fig. 6. Histograms showing changes in the ice pack and in partitioning of incident solar energy between 15 Fune and 7 August 1998.

many floes touched the border of the image, it was not possible to accurately determine the number of floes and the floe size distribution. However, it was straightforward to determine the total floe perimeter in the images. As floes break up, the total perimeter of the ensemble of floes increases. Thus the perimeter provides an indirect proxy of the floe statistics and is also a key parameter for determining the amount of lateral melting (Maykut and Perovich, 1987; Perovich and Maykut, 1990; Steele, 1992). In a simplistic sense, for a given set of atmosphere and ocean conditions, the greater the floe perimeter, the greater the amount of lateral melting. On 15 June the average floe perimeter was $5.5 \mathrm{~km}$ per $\mathrm{km}^{2}$. By 7 August the amount increased by almost an order of magnitude to $44.2 \mathrm{~km}$ per $\mathrm{km}^{2}$, even as the ice concentration decreased due to divergence. To provide perspective for this increase, consider a simple example of the perimeter of a chess board. For a comparable increase in perimeter, the board would have to break into its 64 individual squares.

We believe that there was a significant increase in the total amount of lateral melting associated with the increase in floe perimeter. Observations indicated that lateral melt rates varied considerably throughout the summer, but in general were on the order of $0.05-0.1 \mathrm{~m} \mathrm{~d}^{-1}$ and were relatively high during the divergence event (Perovich and others, 1999a). Using the observed perimeters, and assuming a melt rate of $0.1 \mathrm{md}^{-1}$, the daily change in ice concentration due to lateral melting would be $0.06 \% \mathrm{~d}^{-1}$ for 15 June and $0.4 \% \mathrm{~d}^{-1}$ on 7 August. This assumes, of course, that there is sufficient heat in the upper ocean to support these melt rates.

\section{Impact on partitioning of solar energy}

Understanding the ice-albedo feedback was a major concern of the SHEBA program. To examine the impact of changes in ice morphology on the partitioning of solar energy we will compare results from 15 June 1998 and 7 August 1998 (Fig. 5). We shall simplify and assume that the ice cover on those days consisted of three components: bare ice, melt ponds and leads, with each component represented by a single albedo obtained from observations (Perovich and others, in press b). This is a reasonable simplification since we know that there was little change in the albedo for bare ice, which remained white, and for leads (Pegau and
Paulson, 1999). Some error is introduced by the variability of pond albedos. Observed albedos for 15 June were 0.70 for bare ice and 0.35 for melt ponds. For 7 August, the albedo for bare ice was 0.67 and 0.15 for melt ponds. A lead albedo of 0.06 was used for both days (Pegau and Paulson, 1999). The average albedo for each day was determined by combining the fractional areas of ice, ponds and leads with their respective albedos (Fig. 6).

Estimating the areal average of the solar energy absorbed in the ice and transmitted to the ocean was more difficult. The transmittance is the fraction of the incident solar energy transmitted to the ocean. Not only were there fewer observations of light transmittance, but transmittance is dependent on the ice thickness. Based on observations, we selected transmittance values for ponds and white ice for 15 June $(7 \%, 2 \%)$ and 7 August $(12 \%, 5 \%)$. This analysis did not include any thickness differences. This approach is an oversimplification, but will still provide a rough estimate of the partitioning of the incident solar energy. Radiative transfer modeling and thickness distribution data are needed for a more accurate appraisal.

The areally averaged albedo decreased from 0.67 on 15 June to 0.46 on 7 August. There was no change in the lead albedo and little change in the white-ice albedo during this time. Therefore, this $30 \%$ decrease in albedo was due to a decrease in the melt-pond albedo and an increase in the amount of open water. Associated with the decrease in albedo was an increase in the amount of solar energy input into the ice-ocean system. There was a modest increase in the energy absorbed by the ice from $28 \%$ to $31 \%$, but the major change was a more than four-fold increase in the energy deposited in the ocean from $5 \%$ to $23 \%$. This increase was a direct consequence of the increase in the pond fraction and in the amount of open water.

\section{SUMMARY}

The SHEBA experiment afforded us a rare opportunity to observe the full seasonal evolution of the ice cover, and to identify properties and processes that impact the ice-albedo feedback. In the summer, we observed two major morphological characteristics that significantly affect the ice-albedo feedback. First, the bare ice maintained a relatively high albedo during the summer because it remained white, despite considerable surface melt. Before the experiment, we expected that the albedo of the bare ice would decrease as the summer melt season progressed. This expectation reflected an assumption that at the ice surface the lowdensity ice, which typifies the top 10-30 cm of the multi-year ice, would be replaced by the higher-density, underlying ice as the surface melted. Instead, we found that drainage and fragmentation of the melting ice produces a surface granular layer that continually renews itself throughout the melt season. This low-density surface layer maintains a high albedo.

The second significant morphological characteristic that affects the ice--albedo feedback occurs on a larger scale, involving the summer break-up of the ice pack. We observed that the break-up of the ice pack is caused by a combination of thermodynamic and ice dynamic processes. During the winter, dynamic activity in the consolidated ice pack results in the formation of a network of leads and cracks, which freeze quickly in the cold air temperatures. These cracks are sites of preferential melting in the summer, creating 
discontinuities in the ice cover. After the cracks have melted through, relatively modest dynamic activity is enough to break up the ice cover. Associated with break-up is a change in the distribution of ice and open water, which affects the partitioning of the incoming solar radiation. There is also a large increase in floe perimeter, which enhances the amount of lateral melt. During SHEBA, there was a dynamic event during the summer which resulted in a significant increase in the amount of open water and floe perimeter. We have estimated that these changes, along with the maintenance of a high albedo for the deteriorating bare ice, acted together to cause a significant $(30 \%)$ decrease in the areally averaged albedo.

Future work will involve the application of these observations to improve aggregate scale estimates of solar energy partitioning. Specifically, we will combine measurements of reflectance, absorption and transmittance made on a wide variety of ice types (e.g. first-year ice, multi-year ice, ponded ice) and ice-thickness distribution data with radiative transfer modeling, to link the local and aggregate scales.

\section{REFERENGES}

Ebert, E. E., J. L. Schramm and J. A. Curry. 1995. Disposition of solar radiation in sea ice and the upper ocean. f. Geophys. Res., 100 (C8), 15,965-15,975.

Eicken, H., M. Lensu, M. Leppäranta, W. B. Tucker, III, A. J. Gow and O. Salmela. 1995. Thickness, structure and properties of level summer multiyear ice in the Eurasian sector of the Arctic Ocean. 7. Geophys. Res., $\mathbf{1 0 0}$ (C11), 22,697-22,710.

Fetterer, F. and N. Untersteiner. 1998. Observations of melt ponds on Arctic sea ice. F. Geophys. Res., 103, 24,821-24,835.

Grenfell, T. C. and G. A. Maykut. 1977. The optical properties of ice and snow in the Arctic Basin. 7. Glaciol., 18(80), 445-463.

Ingram, W. J., C. A. Wilson and J. F. B. Mitchell. 1989. Modeling climate change: an assessment of sea ice and surface albedo feedbacks. F. Geophys. Res., 94(D6), 8609-8622.

Maykut, G. A. and D. K. Perovich. 1987. The role of shortwave radiation in the summer decay of a sea-ice cover. 7. Geophys. Res., 92(C7), 7032-7044.

McPhee, M. G. 1980. An analysis of pack ice drift in summer. International Association of Hydrological Sciences Publication 124 (Symposium at Seattle 1977 - Sea Ice Processes and Models), 62-75.

Moritz, R. E. and D. K. Perovich, eds. 1996. Surface heat budget of the Arctic Ocean, science plan. Seattle, WA, University of Washington. Polar Science
Center. Applied Physics Laboratory. SHEBA Project Office. (ARCSS/ OAII Report 5.)

Moritz, R. E., J. A. Curry, A. S. Thorndike and N. Untersteiner. 1993. Surface heat budget of the Arctic Ocean. Seattle, WA, University of Washington. Polar Science Center. Applied Physics Laboratory. SHEBA Project Office. (ARCSS/OAII Tech. Rep 3.)

Pegau, W. S. and C. A. Paulson. 1999. The effects of clouds on the albedo of Arctic leads. [Abstract.] EOS, 80(46), Fall Meeting Supplement, F221.

Perovich, D. K. and G. A. Maykut. 1990. Solar heating of a stratified ocean in the presence of a static ice cover. F. Geophys. Res., 95(C10), 18,233-18,245.

Perovich, D. K. and W. B. Tucker, III. 1997. Arctic sea-ice conditions and the distribution of solar radiation during summer. Ann. Glaciol., 25, 445-450.

Perovich, D. K. and 8 others. 1999a. SHEBA: snow and ice studies. Hanover, NH, U.S. Army Corps of Engineers. Cold Regions Research and Engineering Laboratory.

Perovich, D. K. and 22 others. 1999b. Year on ice gives climate insights. EOS, $\mathbf{8 0}(41), 481,485-486$.

Perovich, D. K., W. B. Tucker, III and K. A. Ligett. In press a. Aerial observations of the evolution of ice surface conditions during summer. F. Geophys. Res.

Perovich, D. K., T. C. Grenfell and B. Light. In press b. The seasonal evolution of Arctic sea-ice albedo. 7. Geophys. Res.

Richter-Menge, J. A., J. E. Overland and S. L. McNutt. 1998. Relating measurements of pack ice stress and deformation in the Alaskan Beaufort Sea. [Abstract.] EOS, 79(45), Fall Meeting Supplement, F436.

Richter-Menge, J. A., D. K. Perovich and S. Pegau. 2001. Summer ice dynamics during SHEBA and its effect on the ocean surface heat content. Ann. Glaciol., 33 (see paper in this volume).

Rind, D., R. Healy, C. Parkinson and D. Martinson. 1995. The role of sea ice in $2 \times \mathrm{CO}_{2}$ climate model sensitivity. Part I: The total influence of seaice thickness and extent. F. Climate, $\mathbf{8}$ (3), 449-463.

Steele, M. 1992. Sea ice melting and floe geometry in a simple ice-ocean model. 7. Geophys. Res., 97 (C11), 17,729-17,738.

Steele, M., J. Zhang, D. Rothrock and H. Stern. 1997. The force balance of sea ice in a numerical model of the Arctic Ocean. 7. Geophys. Res., 102(C9), 21,061-21,079.

Tucker, W. B., III, A. J. Gow, D. A. Meese, H.W. Bosworth and E. Reimnitz. 1999. Physical characteristics of summer sea ice across the Arctic Ocean. 7. Geophys. Res., 104(Cl), 1489-1504.

Untersteiner, N. 1961. On the mass and heat budget of Arctic sea ice. Arch. Meteorol. Geophys. Bioklimatol., Ser. A, 12(2), 151-182.

Weeks, W. F. and S. F. Ackley. 1982. The growth, structure, and properties of sea ice. CRREL Monogr. 82-1.

Williams, F. M. 1994. The Canada/U.S. 1994 Arctic Ocean section ice mechanical properties measurements. St. John's, Nfld, National Research Council of Canada. Institute for Marine Dynamics. (IMD Test Report TR-1994-29.)

Zubov, N. N. 1979. Arctic ice. Hanson, MA, U.S. Air Force. Geophysics Laboratory. (Report AFGL-TR-79-0034.) (L'dy Arktiki. Moscow, Izdatel'stvo Glavsevmorputi, 1945). 